\title{
'It's not as Easy as just Saying 20 Minutes a Day': Exploring Teacher and Principal Experiences Implementing a Provincial Physical Activity Policy
}

\author{
Kristin M. Brown ${ }^{1, *}$, Susan J. Elliott ${ }^{2}$ \\ ${ }^{1}$ School of Public Health and Health Systems, University of Waterloo, Canada \\ ${ }^{2}$ Department of Geography and Environmental Management, University of Waterloo, Canada
}

Copyright (C) 2015 Horizon Research Publishing All rights reserved.

\begin{abstract}
In 2005, the Ontario Ministry of Education implemented the Daily Physical Activity (DPA) Policy to provide every elementary student with at least 20 minutes of sustained moderate to vigorous intensity physical activity each day. This exploratory research sought to understand the factors shaping DPA implementation in schools and classrooms, from the perspective of elementary school teachers and principals. Semi-structured interviews were conducted with Ontario grade 1-8 teachers $(n=14)$ and elementary school principals $(\mathrm{n}=5)$ regarding DPA implementation, facilitators, barriers, perceived outcomes, and suggestions for change. The majority of participants stated that students were not meeting the requirements daily. However, participants shared activities and techniques for incorporating physical activity into instructional time. Facilitators and barriers to implementation were organized using the Analysis Grid for Environments Linked to Obesity (ANGELO) framework in order to identify factors acting at four environmental levels. The facilitators and barriers identified indicate that staff and resources within individual schools strongly influence implementation. Although many positive outcomes for students were identified, increased fitness was not mentioned, highlighting additional benefits above physical health. The findings suggest DPA is not being implemented as intended, as school staff are finding it difficult to meet the time and intensity requirements. Policy makers must consider the local school environment and the roles of school staff when designing school-based health policies.
\end{abstract}

Keywords Physical Activity, School Health, Health Policy, Daily Physical Activity, Social Ecological Theory, ANGELO Framework, Qualitative Methods

\section{Introduction}

Increasing rates of childhood obesity have become a global public health concern [1]. Childhood obesity increases risk for a range of chronic diseases including cardiovascular disease and diabetes and has been linked to negative psychosocial impacts due to bullying [2-4]. One of the major determinants of obesity is physical inactivity [1]. Children's physical activity (PA) levels are alarmingly low $[5,6]$; this is particularly concerning because it has been estimated that more than 5.3 million deaths in 2008 were attributed to physical inactivity [7]. Hence, the World Health Organization (WHO) has established a new target to lower global physical inactivity levels by $10 \%$ by 2025 [8]. Due to the links between physical inactivity and chronic disease in adulthood [9], increasing PA levels in children is likely to have preventative effects in adult life.

Aligning with the WHO recommendations, the 2011 Canadian Physical Activity Guidelines recommend that 5-17 year-olds achieve 60 minutes of moderate to vigorous intensity physical activity (MVPA) per day, including vigorous PA at least three times per week [10]. However, data collected from 2007 to 2009 show that only $7 \%$ of Canadian children and youth are achieving these guidelines [11]. Developing strategies to increase PA levels among children has become a global public health priority [12]. Schools have been described as ideal settings for PA interventions because the target population can be easily reached on a daily basis [13]. Further, there is an emerging area of research that has supported a positive association between PA and academic outcomes [14-16]. WHO [17] suggests that schools provide daily physical education classes; however, only $55 \%$ of Canadian schools have fully implemented a policy for daily physical education [18].

Therefore, alternative school-based PA interventions have been developed. One example is the Ontario Ministry of Education's Policy 138: Daily Physical Activity in Elementary Schools, Grades 1-8 (herein referred to as DPA), which mandates that all grade 1-8 students participate in 20 minutes of sustained MVPA within instructional time each 
day [19]. While we realize that school staff perceptions have been investigated for alternative PA interventions in other jurisdictions internationally (e.g., [20-24]), we believe the unique policy requirements (i.e., that PA must occur during instructional time only) and geographic context of the Ontario DPA policy require exploration. Given the importance of increasing PA levels in children, it is essential to evaluate whether and how PA interventions are reaching their intended goals. Evaluation can determine whether policies are meeting the needs of institutions and populations, leading to improved policy support and implementation [25].

\subsection{Theoretical Context}

Informed by social ecological theory, this qualitative study explores teacher and principal perspectives of factors shaping the implementation and perceived outcomes of DPA in schools and classrooms in the province of Ontario, Canada. Social ecological theory assumes that changes made to the social environment will lead to changes at the individual level [26,27]. Bronfenbrenner [28] introduced the concept of social ecological theory, suggesting that behaviour is affected by multiple levels within an environment, from face-to-face interactions (microsystem) to cultural beliefs and values within a population (macrosystem). The theory also assumes that individuals within each level influence the environment [29]. In order to implement environmental changes, individuals within that population must be supportive [26,27]. Further, the effectiveness of an intervention depends on the fit between individuals and their environment, as well as the characteristics of the setting where it takes place $[29,30]$.

When applied to health promotion, social ecological theory implies that individuals' environments influence their health behaviours and alterations to the environment can lead to improved health of individuals [31]. The underlying assumption of DPA is that mandating schools to provide students with 20 minutes of PA per day will lead to more active and healthier students. Hence, social ecological theory suggests that factors at the classroom, school, school board/district, and provincial levels influence DPA implementation and outcomes. If individuals at the school board, school, or classroom level do not value the importance of PA, DPA may not be implemented as intended in classrooms.

In order to frame the factors acting at each environmental level, the findings are organized using the Analysis Grid for Environments Linked to Obesity (ANGELO) framework, as described by Swinburn et al. [32]. The ANGELO framework divides the environment into two scales: micro (known as 'settings', including classrooms and schools) and macro (known as 'sectors', including the education system). Within the micro- and macroenvironments, there are physical, economic, sociocultural, and political environments, and factors within each influence implementation. The physical environment describes what is available, while the economic environment includes the costs. The sociocultural environment reflects the values, beliefs, and attitudes of a group towards PA, and the political environment refers to 'laws, regulations, policies (informal or formal), and institutional rules' ([32], p. 567). While the ANGELO framework was designed to investigate the environmental factors influencing obesity as an outcome, it has also been used to explore the factors that influence PA within communities [33,34] as well as nutrition interventions [35-37]. Hence, it is useful for framing the investigation of the research questions here. Using the ANGELO framework to shape the design and analysis of the work allows facilitators and barriers to emerge across a range of spatial scales, providing more nuanced clues for policy and decision makers regarding appropriate interventions.

\subsection{Research Context}

The DPA policy states that on days when there is no physical education class or when the physical education class does not involve PA (i.e., a health class), twenty minutes of sustained MVPA must be provided during instructional time [19]. Suggested strategies include integrating PA into other subjects and combining short sessions to reach the 20 minutes. School boards and principals are responsible for ensuring and monitoring implementation [19]. However, concerns have been identified around monitoring and evaluation of the policy [38,39]. The importance of determining how it has been implemented and whether the intended outcomes are being achieved has been stressed [40]. Researchers suggest that in order to answer these questions, we ask the key stakeholders on the ground $[38,39,41]$.

To date, only two studies have evaluated DPA. Using accelerometry to study grade five and six students in Toronto, Stone et al. [42] found less than half of the students received DPA daily, and no students met the sustained MVPA requirement. However, students who participated in DPA daily had higher activity levels; thus, Stone et al. [42] argued DPA could lead to positive health outcomes if implemented as intended. Surveying teachers from the London, Ontario area, Patton [43] found more than half were sometimes, rarely, or never implementing DPA, citing time and limited monitoring as the greatest barriers to implementation. Teachers indicated they had limited time for planning and conducting DPA, and that DPA 'diverted time away from other subjects' ([43], p. 18).

Although Stone et al. [42] found variation in DPA implementation and outcomes between schools, they did not examine how or why this variation occurs. Patton's [43] quantitative survey opens the door to understanding, but he poses the following question:

So why do teachers find it so hard to find the time to conduct the program and why do so many teachers report that DPA takes valuable time away from other subjects? [...] This misunderstanding of the impact of DPA must be addressed. (p. 20) 
To address the above question, we must explore key stakeholders' perceptions of the factors affecting their classroom activities. Qualitative methods are essential to understanding the context of intervention settings [44]. Informed by social ecological theory, this qualitative study builds on previous work by exploring teacher and principal perspectives regarding factors shaping the implementation and perceived outcomes of DPA in schools and classrooms in the province of Ontario, Canada.

\section{Materials and Methods}

In order to better understand the factors affecting DPA implementation at the ground level, we need to start with the microenvironment; that is, the level of the school and the classroom. Additionally, principals are able to provide insight around factors at the macroenvironment (i.e., institutional) level of the school board/district. Semi-structured interviews were conducted with elementary school teachers $(n=14)$ and principals $(n=5)$ across 16 schools from 8 school boards in Ontario. Any teacher who taught grades 1-8 (students aged 5-13) or administrator (i.e., principal or vice-principal) at a publically funded elementary school in Ontario was eligible to participate. The purposeful sampling strategy of maximum variation was used in order to gain a broad range of perspectives within the participant groups [45]. We employed multiple recruitment strategies and created online advertisements targeted to different geographic areas of the province in order to increase the likelihood of achieving maximum variation.

Table 1. Participant Characteristics.

\begin{tabular}{|c|c|c|}
\hline Personal Characteristic & $\begin{array}{c}\text { Number of Teachers } \\
(\% \text { of total })\end{array}$ & $\begin{array}{c}\text { Number of Principals } \\
(\% \text { of total })\end{array}$ \\
\hline \multicolumn{3}{|l|}{ Current Grade Taught } \\
\hline Primary (Grade 1-3) & $5(36)$ & - \\
\hline Junior (Grade 4-6) & $4(29)$ & - \\
\hline Intermediate (Grade 7-8) & $3(21)$ & - \\
\hline Special Education & $2(14)$ & - \\
\hline Number of Years of Experience & (Teaching) & (Administrative) \\
\hline $0-5$ years & $2(14)$ & $0(0)$ \\
\hline $6-9$ years & $3(21)$ & $3(60)$ \\
\hline $10-15$ years & $5(36)$ & $2(40)$ \\
\hline More than 15 years & $4(29)$ & $0(0)$ \\
\hline \multicolumn{3}{|l|}{ Number of Years as Administrator at Current School } \\
\hline $1-2$ years & - & $3(60)$ \\
\hline $3-5$ years & - & $2(40)$ \\
\hline \multicolumn{3}{|l|}{$\begin{array}{l}\text { Number of Years Since Last Post-Secondary Training } \\
\text { (i.e., teachers' college, university course(s)) }\end{array}$} \\
\hline Within last 5 years & $3(21)$ & $2(40)$ \\
\hline 5-10 years & $4(29)$ & $0(0)$ \\
\hline $10-15$ years & $4(29)$ & $2(40)$ \\
\hline More than 15 years ago & $3(21)$ & $0(0)$ \\
\hline Unknown & $0(0)$ & $1(20)$ \\
\hline \multicolumn{3}{|l|}{$\begin{array}{l}\text { Specialized Training in Health \& Physical Education } \\
\text { (i.e., undergraduate, teachers' college degree) }\end{array}$} \\
\hline No & $11(79)$ & $4(80)$ \\
\hline Yes & $3(21)$ & $1(20)$ \\
\hline \multicolumn{3}{|l|}{$\begin{array}{l}\text { Has Attended Professional Development Session(s) } \\
\text { for DPA/Physical Education }\end{array}$} \\
\hline Yes & $9(64)$ & - \\
\hline No & $5(36)$ & - \\
\hline \multicolumn{3}{|l|}{$\begin{array}{l}\text { Self-Reported Physical Activity Status (compared to } \\
\text { Canadian Physical Activity Guidelines for Adults) }\end{array}$} \\
\hline Very physically active (exceeds standard) & $4(29)$ & $0(0)$ \\
\hline Physically active (meets standard) & $7(50)$ & $3(60)$ \\
\hline Not very physically active (below standard) & $3(21)$ & $2(40)$ \\
\hline Total & $14(100)$ & $5(100)$ \\
\hline
\end{tabular}

Note: - Question was not asked of the respective key informant group 
Table 2. Characteristics of Participants' Schools

\begin{tabular}{|c|c|c|}
\hline School Characteristic & $\begin{array}{c}\text { Number of Teachers } \\
\text { (\% of total) }\end{array}$ & $\begin{array}{c}\text { Number of Principals } \\
\text { (\% of total) }\end{array}$ \\
\hline \multicolumn{3}{|l|}{ Type of School Board } \\
\hline Public & $12(86)$ & $4(80)$ \\
\hline Catholic & $2(14)$ & $1(20)$ \\
\hline \multicolumn{3}{|l|}{ Grades in Current School } \\
\hline Junior Kindergarten-Gr. 8 & $8(57)$ & $4(80)$ \\
\hline Junior Kindergarten-Gr. 6 & $4(29)$ & $0(0)$ \\
\hline Junior Kindergarten-Gr. 4 & $2(14)$ & $0(0)$ \\
\hline Alternative elementary school & $0(0)$ & $1(20)$ \\
\hline \multicolumn{3}{|l|}{ Number of Students in Current School } \\
\hline Less than 400 & $4(29)$ & $3(60)$ \\
\hline $400-600$ & $7(50)$ & $2(40)$ \\
\hline More than 600 & $3(21)$ & $0(0)$ \\
\hline \multicolumn{3}{|l|}{ Location of School } \\
\hline Urban & $11(79)$ & $5(100)$ \\
\hline Rural & $3(21)$ & $0(0)$ \\
\hline \multicolumn{3}{|c|}{ French Immersion Program(s) Available at School } \\
\hline No & $9(64)$ & $4(80)$ \\
\hline Yes & $5(36)$ & $1(20)$ \\
\hline Total & $14(100)$ & $5(100)$ \\
\hline
\end{tabular}

After receiving ethics approval from the University of Waterloo Office of Research Ethics, participants were recruited through online advertisements on Kijiji, a free classifieds website; the researchers also forwarded these advertisements by email through their networks (i.e., researchers at the university who conducted research in school settings). Lastly, snowball sampling allowed the researchers to find information-rich stakeholders by asking participants to suggest valuable informants [46]. Specifically, participants were asked, 'Is there anyone else that you think I should talk to regarding DPA implementation?' and the participant provided the suggested individual with the researcher's contact information. Sampling to the point of saturation (i.e., where no new themes emerged with additional participants) was used to determine the final sample size for each key informant group. More teacher interviews than principal interviews were required to reach saturation, as there was greater variance in the teachers' implementation experiences compared to principals. This is likely because teachers are directly responsible for implementing DPA in their classrooms while principals oversee the policy.

The teacher sample consisted of eleven females and three males, from twelve schools in seven school boards, while the two female and three male principals were from five schools in three school boards (Table 1). Only one teacher-principal pair was from the same school. In total, participants represented sixteen schools from eight school boards in Southwestern, Central, Eastern, and Northern Ontario (Table 2). Only three teachers and one principal had a post-secondary degree in Health and Physical Education; this is important to note since many generalist teachers (i.e., those without Health and Physical Education training) are responsible for providing DPA.

Key informants were interviewed individually by phone $(n=16)$ or in-person $(n=3)$ between October 2012 and January 2013. Teacher interviews were conducted after school or on weekends to avoid disrupting instructional time. Interviews lasted 25-75 minutes and were digitally audio-recorded with permission. The interview questions were informed by social ecological theory and the ANGELO framework. Key informants completed a questionnaire (in writing or verbally) immediately following the interview to provide relevant demographic information. All participants received a $\$ 20$ bookstore gift card in appreciation.

Interviews were transcribed verbatim and proofed for accuracy prior to thematic analysis using computer assisted qualitative data analysis software, NVivo9. In so doing, the researcher listened to the interview recording while reading the transcript to ensure accuracy of transcription. A template organizing style was used, which involved developing a set of codes to identify relevant data [45]. Transcripts were read in order to determine codes to compose coding manuals for each participant group. The coding manuals were then used to code the transcripts. These codes were then organized by themes and sub-themes, guided by the ANGELO framework. First, a deductive approach was used to explore the data for themes elicited by way of the interview schedule. Second, themes that emerged inductively from the interview transcripts were tagged. In the end, five main themes were 
identified from the deductive analysis. Among and within these, several sub-themes emerged inductively from the qualitative analysis. 1

\section{Results}

The results are organized around five key themes: DPA implementation strategies, perceived facilitators and barriers to implementation, perceived outcomes of DPA, and suggestions for change. These are discussed in turn, with key findings punctuated by participants' voices through transcript quotations.

\subsection{Implementation Strategies}

Twelve teachers had implemented DPA in their classes and all principals $(\mathrm{n}=5)$ said their schools had implemented DPA. However, $80 \%$ of principals and $64 \%$ of teachers indicated students were not necessarily meeting the guidelines daily. This indicates that although schools are trying to implement DPA, they are not necessarily meeting the guidelines. Only two teachers' schools had daily physical education classes; therefore, the other 14 schools had to provide additional activities in order to meet the DPA time requirements.

Teachers discussed strategies they used to implement DPA. Seven teachers discussed how students often generated DPA activity ideas and led activities, while two teachers and one principal described programs at their schools that involved older students leading DPA sessions in the younger classes:

Well I would come in with some crazy dance to a song, and I would teach it to them, [...] if you show me you and your group can do it, I am going to send you now to the grade four class, [...] and so then I would send little groups of four students into each class in the whole school and teach it to them. And then at the next assembly I would send my class up on stage and then they would lead the song, and then of course everyone in the whole school would have known it. (Teacher 9, female)

Teachers discussed meeting the DPA time requirement by integrating PA into other subjects $(\mathrm{n}=5)$ and through multiple breaks during the day that sum to 20 minutes, instead of one 20-minute period $(\mathrm{n}=6)$ :

For me, I always try to incorporate it into the lessons as well, as much as you can into literacy and math, and add activity so it is not always like I say, a twenty minute workout, but over the day you'd get that activity. (Teacher 13, female)

1 Inter- and intra-rater reliability were assessed using the methods described by Miles and Huberman [47]. Both inter- and intra-rater reliability were calculated to be above $75 \%$ [47].
Lastly, one principal discussed how the school's weekly schedule was designed to include three physical education periods and one health period in which the teacher led 20 minutes of DPA. That way, many homeroom teachers were only responsible for implementing DPA in their classrooms once per week:

Every student in our school gets three gym classes in the big double gym, even kindergarten. And then everybody gets one health class on top of that, and that health class must begin with [DPA], so there is your four in a week. And then the fifth one has to come out of a day when you don't have [health or physical education], to do it out of your language time, just fifteen minutes or so of [DPA]. (Principal 3, male)

Teachers also discussed the activities they used for DPA. The most common activities in the classroom were dancing and games $(\mathrm{n}=8)$, followed by stretching, yoga and those that included music $(\mathrm{n}=6)$, and fitness circuits $(\mathrm{n}=5)$ :

We do a lot of little dances or sort of minor aerobic activities. We are doing sort of, you know, not a step class, but something like that. And you know, sometimes I even, on the way back from the gym, I have ten minutes where we do yoga poses and that type of thing. (Teacher 11, female)

Teachers discussed how it was easier to achieve MVPA in larger spaces than in the classroom. In large indoor (e.g., gyms, activity rooms) and outdoor spaces, the most common activities described were running $(\mathrm{n}=5)$ and sports $(\mathrm{n}=4)$ :

So when I do take them outside or I do have more space, I can engage them more to get their heart rates up. But in the classroom I definitely have a hard time with that, because like I say they are juggling, they are doing, you know, maybe high steps beside their desk, high knees or things like that. But they are marching. They are not running. (Teacher 14, female)

In sum, teachers employed several strategies including multiple breaks throughout the day, student-led activities, and the integration of PA into other subjects. They also noted space limitations of in-class activities.

\subsection{Implementation Facilitators}

All factors that influenced DPA implementation (i.e., facilitators and barriers) are presented in 3, organized using the ANGELO framework. Teacher-specific factors (i.e., motivation, comfort level, and experience with PA) were the most frequently discussed facilitators to DPA implementation. For instance, all teachers and three principals mentioned teachers must be motivated to successfully implement DPA:

I think the biggest thing quite honestly is the buy-in of staff. They have to see the benefits that it has for the students and their ability. (Principal 5, female). 
Table 3. Facilitators and barriers organized using the ANGELO framework (adapted from Swinburn et al. 1999).

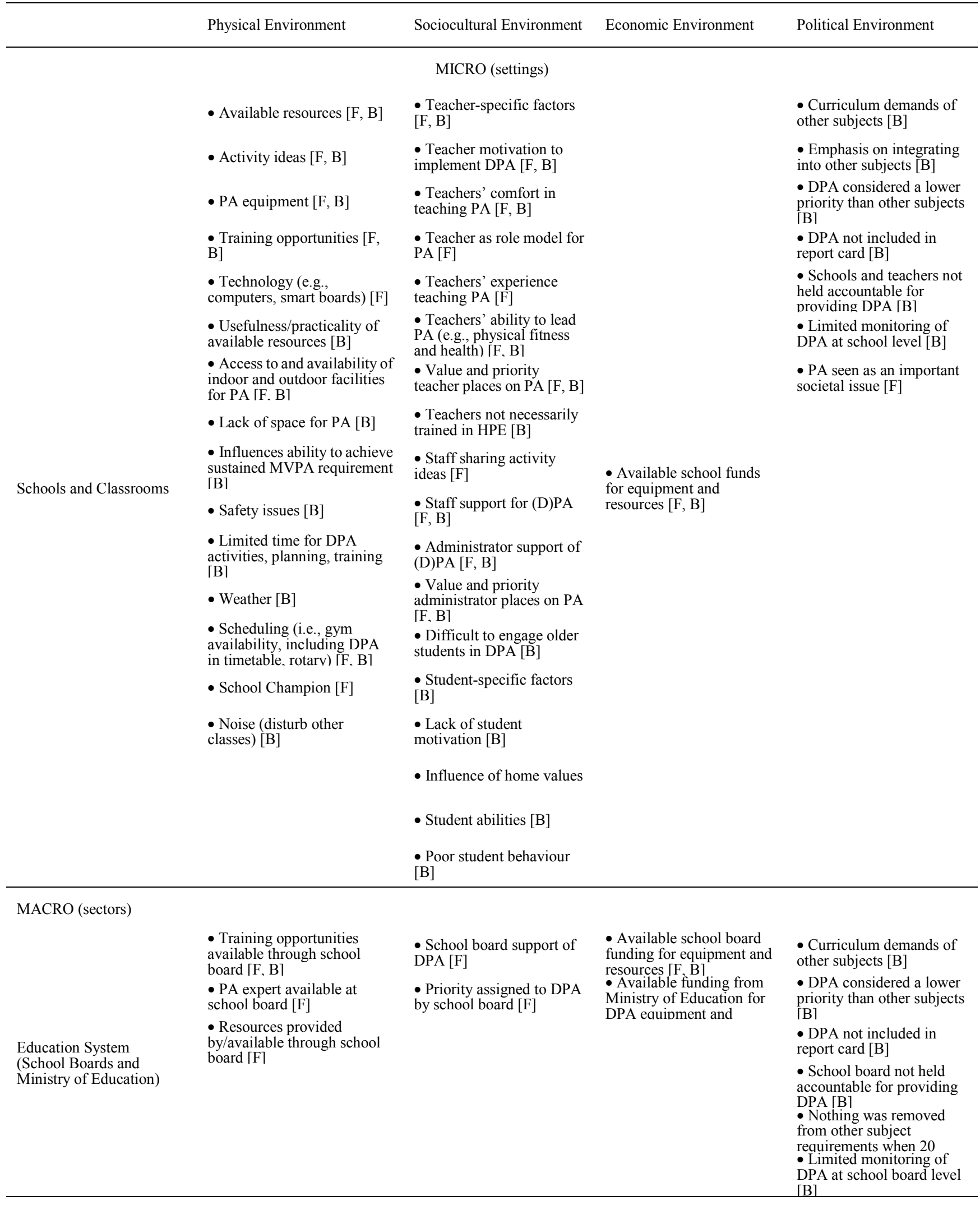


Similarly, Teacher 6 (male) suggested the following:

I think any activity can work as long as the person who is delivering the [DPA] is enthusiastic and energetic, does it with the kids.

All participants discussed the school's social environment as a facilitator, including the importance of sharing ideas between teachers, administrator support, and having a school champion (i.e., someone who leads DPA implementation within the school):

Talking to your colleagues. [...] That is the biggest support in teaching, is just, 'What do you do? Have you tried this?' And you know, when you get a good idea, share it. (Teacher 4, female).

Both groups $(n=12, n=5)$ discussed the importance of easily accessible activity ideas and equipment:

When DPA first came out, there were regular emails that came out with ideas and suggestions. [...] they were really useful, because it gave you something practical that you could use and implement. (Teacher 12 , female).

Attending training sessions for DPA was a perceived facilitator, although some teachers noted many DPA training opportunities were optional and offered infrequently:

But the [professional development] session was entirely voluntary. [...] And I can remember doing one of the [DPA sessions], so I probably was one or two of the only teachers in our school that did it. (Teacher 6, male).

Participants $(n=10, n=4)$ discussed how the school physical environment (i.e., available facilities and outdoor space) was an asset to implementation:

We are by a park and we are by a high school, so there are always opportunities to have daily physical activity outside on a nice day. (Principal 1, female).

Lastly, scheduling DPA sessions into the timetable ( $\mathrm{n}=7$, $\mathrm{n}=3)$ and school board support $(\mathrm{n}=6, \mathrm{n}=4)$ were seen as facilitators:

Our board has done a good job. Like we have had workshops for admin, workshops for phys. ed. teachers, and staff contacts, so I think there is a real push, you know, from the senior folks at our board to make sure that we are doing it. (Principal 3, male)

\subsection{Implementation Barriers}

Although both groups identified similar themes, teachers discussed more barriers than principals. All participants described features of the school physical environment as barriers, including limited access to PA facilities:
The school has nine portable [classrooms] 2 [...] and for next year we are projected for 1000 students. So all of that with the same gym facilities that we had when we opened for 375 students. (Teacher 4, female).

Teachers $(\mathrm{n}=11)$ emphasized limited classroom space as a major barrier, since there was inadequate room for students to perform DPA activities, leading to safety concerns and making it difficult to achieve MVPA:

I can't get their heart rate up for five or ten minutes in that space. It is too dangerous with that many bodies, and that little clearance of furniture. (Teacher 8, female).

Resources also presented a barrier, including limited equipment, funding, activity ideas, and training opportunities:

[...] [teachers] don't know what to do, they're out of ideas. So I think that's the biggest roadblock. [...] finding a way to give teachers pre-made activities. (Teacher 1, female).

The second-most frequently mentioned barriers were curricular demands and limited time for DPA $(n=13, n=4)$ :

Am I going to give up that twenty minutes of DPA or am I going to give up, you know, that twenty minutes of math that we didn't quite get to? (Principal 5, female).

Teachers highlighted disruptions such as school events that decrease the time they can devote to DPA:

It would be a week like we didn't make it to the gym at all. Partly because it is a really busy school, and I just pray for one regular day. It doesn't happen. (Teacher 2, male).

Participants emphasized that DPA is considered a lower priority than the other subjects because DPA is not included in report cards and there is no consequence if they do not meet the guidelines:

I have to be honest, while I value it in terms of my day, it is not reportable; please do not be offended, it is not a priority for me. (Principal 4, male).

Similarly, Teacher 5 (female) stated,

The kids are not being marked on [DPA] either, so there is no grade that you have to give them. It is just something that you would hope is being done.

Participants discussed how DPA is more difficult to implement in the older grades $(n=12, n=2)$, due to greater curricular demands, difficulty engaging older students, and rotary 3 :

2 A 'portable classroom' is a temporary building on school property that is separate from the main school building. It is used to accommodate classes when the main school building does not have enough space for all of its classes.

3 Rotary is a term used to describe a class in which the students move between classrooms and teachers for different subjects (as opposed to being taught by their homeroom teacher for the majority of their subjects). In Ontario, rotary is typical for grade 7 and 8 students. 
You have to do something that [older students] are going to buy into, and they don't always buy into 'okay, we are going to roll the dice and if we roll five, now we are going to do five chicken jacks'. (Teacher 6, male)

Lack of student motivation was identified by eleven teachers, who discussed how some students did not want to participate or it was difficult to keep the activities 'fresh' to prevent student boredom. Similarly, participants $(n=10, n=3)$ discussed teacher-specific characteristics, including that some teachers are not comfortable teaching PA and others are unmotivated to implement DPA:

I don't have the right shoes, I am not changed, it's just not easy. And it is also, you don't want to put yourself out there, like you need to know everything and be good at everything so they will listen to you. (Teacher 2, male)

Lastly, five teachers and one principal argued that although the policy is well intended, implementation was not necessarily feasible in existing school environments:

I really like the idea of kids being active, and definitely believe it benefits their learning, but I don't think it has been well thought through as to how does that actually work in a regular day in a regular classroom, which may or may not be in a school building, with or without access to a gym. (Teacher 4 , female)

The majority of teachers and principals that discussed school-level monitoring of DPA said they were unaware of any occurring, even though the policy states this is the responsibility of principals. All but one of the teachers and principals who discussed board-level monitoring were unaware of any occurring:

Are we checking with teachers to make sure they are doing it? No. Is the board checking with us to make sure we are doing it? Not that I know of. (Principal 3, male).

The few participants who were aware of monitoring described holding staff meetings to evaluate implementation and principals conducting observations to assess whether DPA was occurring in their schools.

\subsection{Outcomes}

The majority of outcomes discussed by participants were positive. Most focused on student outcomes; however, some teachers also reported class, school, and teacher impacts. Although participants only had experiential evidence for a link between DPA and academic outcomes, they discussed students' increased focus and attention in other subjects $(\mathrm{n}=11, \mathrm{n}=3)$ :

If they are moving and active, they are better able to focus on the language and the math. (Teacher 3, female).
Twelve teachers stated DPA provides students with a break during the school day:

[...] 'We are going to do some DPA here, and then we will finish off our language later'. Because you just see the kids starting to zone out and you know you need to get them up and moving. (Teacher 9, female)

It gives them a break from the academics, [...] It gives them that time to go and get active and get rid of all the stress of the learning, which I know a lot of kids do struggle with school, clear their heads and come back energized and ready to go again. (Teacher 7, female)

Teachers stated students enjoy DPA $(n=11)$ and it provides leadership opportunities $(\mathrm{n}=8)$, as students can lead, or share ideas for, activities:

The kids never, at the age group I am working with [grade 5], they never run out of options to bring forth. They love the idea that they get to suggest the game and get selected. That is a big thing for them. (Teacher 8, female)

Teachers also mentioned that DPA improved the overall class environment and provided an opportunity for students to interact in an informal, fun setting:

The general mood of the class, like doing a physical activity together is kind of a bonding time for a class. [...] they laugh, and it is fun, and they feel good. (Teacher 4, female).

Similarly, three teachers mentioned these positive class outcomes could spread throughout the school, especially when there are student leaders or DPA activities at assemblies.

Eight teachers and one principal discussed negative outcomes of DPA. Teachers said it was sometimes difficult for students to settle down after DPA $(n=6)$ and DPA increased teachers' stress $(n=4)$ :

[DPA] put more pressure on the backs of an already stressed teaching group. And I don't think any one of us would argue that we don't think it is a good thing, or we don't want to do more of it. [...] I find it a struggle to come up with new and quick and easy things that are fun and fresh. (Teacher 8, female)

The principal mentioned that some teachers view DPA as a break from instruction:

I think one of the concerns is that we have teachers who are not physically fit themselves or don't know how to handle that unstructured time. And so what will happen is if they don't have a plan [for DPA] and they go out, sometimes kids are just playing on the monkey bars or on [playground] equipment rather than organizing a quick game in the classroom. (Principal 4, male)

Participants did not mention increased PA levels as an outcome; in fact, four teachers questioned whether DPA was actually increasing student PA levels, the intended goal of 
the policy.

\subsection{Suggestions for change}

Although DPA was considered a lower priority than other subjects, all participants discussed the importance of increasing children's PA levels. Six teachers and three principals recognized the link between PA and learning:

[...] there is value in it from a healthy active lifestyle perspective, but also from an academic one. Kids [who] are active do better in school and pay attention better. (Principal 3, male).

Participants debated whether it was the responsibility of schools, parents, or society to increase children's PA levels:

So making things affordable or free, you know, having programs for kids so that they can access different sports and activities after school hours, and I think that would be of great benefit, more than putting the onus on the school. (Principal 5, female)

Participants suggested changes to DPA implementation; six teachers emphasized the need for more space:

Gym every day, or if we didn't have gym every day, at least have a vacant classroom where you could take the kids and they could do DPA. [...] But convincing the board or anyone to allow that space is going to be a really, really tough battle. (Teacher 14 , female)

Five teachers and two principals discussed increasing accountability through monitoring DPA or including it in student report cards:

Once there is that accountability piece, then oh, you better believe you will have teachers doing twenty minutes of [DPA]. (Teacher 6, male).

Similarly:

So really until it is monitored, whether by check mark or, you know, reported on, I doubt we will see a change in it. (Principal 4, male).

Eight teachers discussed increasing resources, equipment, and activity ideas, while six teachers recommended having a PA expert (e.g., teacher or fitness instructor) available at the school or board level to help teachers implement DPA and provide resources:

It would be really nice to have somebody who was the expert. [...] They come in and they teach you how you can implement DPA into your classroom and do a sample lesson. (Teacher 7, female).

\section{Discussion}

This study contributes to our understanding of teachers' and principals' experiences with the implementation of PA policies designed to enhance children's health. Specifically, it offers insight into how DPA is being implemented at the school and classroom levels. Consistent with previous studies $[42,43]$, participants indicated their classes/schools were not meeting the DPA guidelines. We further found that even when activity occurred, teachers perceived students were not meeting the prescribed intensity given severe space limitations within the classroom. This may perhaps be a function of the policy intent given DPA is meant to occur during instructional time. That is, while the policy states DPA must occur within instructional time, it does not recognize the difficulties of reaching sustained MVPA in the small space of a classroom. These findings align with Stone et al.'s [42] proposition that achieving the sustained MVPA component of DPA could be 'logistically challenging' ( $p$. 173).

When the implementation facilitators were organized using the ANGELO framework (Table 3), it was evident that teachers focused on facilitators within the sociocultural and physical environments. Both groups emphasized facilitators within the class, school, and school board levels and did not mention factors at the provincial level. For example, participants discussed how teachers were more likely to implement DPA when they felt comfortable teaching PA and resources were shared among the school staff, aligning with the extant literature $[23,48]$. This is consistent with social ecological theory; individuals within a population must be supportive of interventions in order for change to occur $[26,27]$.

Perceived barriers were also related to the local teaching environment. Barriers were identified in all four environments and both environmental scales (Table 3 ). This study expands on previous literature identifying space constraints as a barrier $[43,49]$ by highlighting how space constraints cause safety concerns and prevent students from meeting the intensity requirements. Further, participants emphasized that DPA is a lower priority than other subjects because it is not reportable, consistent with studies of other school-based PA interventions [22,41,50,51]. Principals tended to mention factors within the political and economic environments (e.g., school board's influence and funds allocated to DPA) more than teachers, likely due to their roles. Overall, the findings show that local-level factors influence delivery and the ANGELO framework proved useful for organizing these factors.

Despite rare reports of negative outcomes (e.g., it was difficult for students to settle after DPA), both teachers and principals primarily focused on positive student outcomes, including increased focus and attention. Teachers described how DPA provides students with a break from academics as well as potential leadership opportunities. A particularly interesting finding of this research was that both teachers and principals, when probed about positive outcomes, did not necessarily describe outcomes related to health or fitness. Rather, they discussed academic (e.g., greater focus) and social (e.g., leadership opportunities) outcomes, aligning with previous literature $[23,52]$. Thus, the current research 
indicates that school-based PA interventions are perceived to positively influence the classroom environment, leading to improved student learning and social skill development over and above any potential physical health benefits.

Although the Ontario Ministry of Education outlined school board and principal responsibilities for monitoring implementation of the policy $[19,53]$, these findings suggest school boards and principals are not being held accountable. DPA is not a reportable item on student report cards, unlike other subjects (e.g., mathematics and English). As a result, administrators and teachers have to make tough decisions regarding priorities within the curriculum. Limited accountability has also been identified for American school wellness policies [54,55] and Canadian jurisdictions [23,43]. The participants in this research highlighted the importance of increasing monitoring and accountability to improve DPA implementation, suggesting DPA should become a reportable subject. By including DPA in report cards, meeting the guidelines would be viewed as a higher priority by school boards, principals, and teachers. An additional strategy could include implementing formal DPA monitoring procedures in schools and school boards. While following this strategy addresses the issues raised by teachers and principals, it could also be construed as a way to externalize the blame for the policy's failure, shifting the focus from teachers' inability to implement the policy to macro-level structural factors.

\section{Limitations and Future Research}

Although the purpose was not to generalize, a limitation to this research is the relatively small sample size (19 participants). However, views from individuals in sixteen schools and eight school boards were represented and sampling for each participant group concluded when saturation was reached. The findings of this study can inform further qualitative studies of other key informant groups (e.g., school boards, Ontario Ministry of Education, and students) in order to gain a full-scale perspective of DPA implementation. A second limitation is the teacher sample was $78 \%$ female but this is fairly representative as the Ontario elementary teacher population is only $20-30 \%$ male $[56,57]$.

\section{Conclusions}

This research includes both principal and teacher perspectives of DPA, filling a gap previously identified in the literature $[38,39]$. The findings show that although the DPA guidelines apply across Ontario schools and school boards, the degree of implementation is shaped by the local environment. The findings suggest school stakeholders believe increasing PA levels is valuable; however, the current school setting limits the feasibility of implementation. In order to improve delivery, school-based PA policies must be seen as a priority at the class, school, district, and provincial/state levels and monitoring of implementation must be conducted. Further consideration of implementation logistics is necessary in order to increase the likelihood of meeting the policy requirements. Theoretically, this study provides an example of how the ANGELO framework can be used to evaluate a PA intervention. This is a key contribution as the framework has mainly been used to evaluate features that promote or inhibit obesity within an environment (see $[33,58,59]$ ) and to organize reviews of studies or policy documents (see [60-63]). This work contributes to the limited evaluation of DPA and indicates that currently, the policy may not be implemented as intended and may not lead to the anticipated fitness outcomes. Overall, when designing school-based PA policies, policy makers should consider the priorities of local-level stakeholders as well as the resources and expertise available for implementation.

\section{Acknowledgments}

Stipend support to KMB funded by Cancer Care Ontario and the CIHR Training Grant in Population Intervention for Chronic Disease Prevention: A Pan-Canadian Program (Grant \#53893) and an Ontario Graduate Scholarship from the Ontario Ministry of Training, Colleges, and Universities.

\section{REFERENCES}

[1] S. Karnik A. Kanekar. Childhood obesity: A global public health crisis. International Journal of Preventive Medicine, Vol. 3, No. 1, 1-7, 2012.

[2] I. Janssen, W. M. Craig, W. F. Boyce, W. Pickett. Associations between overweight and obesity with bullying behaviors in school-aged children, Pediatrics, Vol. 113, No. 51, 1187-94, 2004.

[3] D. S. Freedman, Z. Mei, S. R. Srinivasan, G. S. Berenson, W. H. Dietz. Cardiovascular risk factors and excess adiposity among overweight children and adolescents: The Bogalusa heart study, Journal of Pediatrics, Vol. 150, No. 1, 12-17.e2, 2007.

[4] M. H. Park, C. Falconer, R. M. Viner, S. Kinra. The impact of childhood obesity on morbidity and mortality in adulthood: A systematic review, Obesity Reviews, Vol. 13, No. 11, 985-1000, 2012.

[5] M. Tremblay, C. Gray, K. Akinroye, D. Harrington, P. Katzmarzyk, E. Lambert, G. Tomkinson. Physical activity of children: A global matrix of grades comparing 15 countries, Journal of Physical Activity and Health, Vol. 11, No. S1, S113-25, 2014.

[6] P. C. Hallal, L. B. Andersen, F. C. Bull, R. Guthold, W. Haskell, U. Ekelund. Global physical activity levels: Surveillance progress, pitfalls, and prospects, The Lancet, Vol. 380, No. 9838, 247-57, 2012. 
[7] I. Lee, E. J. Shiroma, F. Lobelo, P. Puska, S. N. Blair, P. T. Katzmarzyk. Effect of physical inactivity on major non-communicable diseases worldwide: An analysis of burden of disease and life expectancy, The Lancet, Vol. 380, No. 9838, 219-229, 2012.

[8] World Health Organization. Global action plan for the prevention and control of noncommunicable diseases 2013-2020, Online available from http://apps.who.int/iris/bitstream/10665/94384/1/978924150 6236_eng.pdf?ua $=1$.

[9] D. E. R. Warburton, S. Charlesworth, A. Ivey, L. Nettlefold, S. S. D. Bredin. A systematic review of the evidence for Canada's physical activity guidelines for adults, International Journal of Behavioral Nutrition and Physical Activity, Vol. 7, No. 39, 2010.

[10] M. S. Tremblay, D. E. Warburton, I. Janssen, D. H. Paterson, A. E. Latimer, R. E. Rhodes, M. E. Kho, A. Hicks, A. G. LeBlanc, L. Zehr. New Canadian physical activity guidelines. Applied Physiology, Nutrition, and Metabolism, Vol. 36, No. 1, 36-46, 2011.

[11] R. C. Colley, D. Garriguet, I. Janssen, C. L. Craig, J. Clarke, M. S. Tremblay. Physical activity of Canadian children and youth: Accelerometer results from the 2007 to 2009 Canadian health measures survey, Health Reports, Vol. 22, No. 1, 15-23, 2011.

[12] M. Dobbins, H. Husson, K. DeCorby, R. L. LaRocca. School-based physical activity programs for promoting physical activity and fitness in children and adolescents aged 6 to 18 , Cochrane database of systematic reviews, No. 2, 2013.

[13] S. Kriemler, U. Meyer, E. Martin, E. M. F. van Sluijs, L. B. Andersen, B. W. Martin. Effect of school-based interventions on physical activity and fitness in children and adolescents: A review of reviews and systematic update, British Journal of Sports Medicine, Vol. 45, No. 11, 923-30, 2011.

[14] F. Trudeau, R. J. Shephard. Physical education, school physical activity, school sports and academic performance, International Journal of Behavioral Nutrition and Physical Activity, Vol. 5, No. 10, 2008.

[15] A. L. Fedewa, S. Ahn. The effects of physical activity and physical fitness on children's achievement and cognitive outcomes: A meta-analysis. Research Quarterly for Exercise and Sport. Vol. 82, No. 3, 521-35, 2011.

[16] C. N. Rasberry, S. M. Lee, L. Robin, B. A. Laris, L. A. Russell, K. K. Coyle, A. J. Nihiser. The association between school-based physical activity, including physical education, and academic performance: A systematic review of the literature. Preventive Medicine. Vol. 52, No. S1, S10-20, 2011.

[17] World Health Organization. A guide for population-based approaches to increasing levels of physical activity. implementation of the WHO global strategy on diet, physical activity, and health, Online available from http://www.who.int/dietphysicalactivity/PA-promotionguide -2007.pdf

[18] Canadian Fitness and Lifestyle Research Institute. Encouraging active schools: 2011 opportunities for physical activity at school survey, Online available from http://www.cflri.ca/media/node/1054/files/Schools\%202011
\%20Bulletin\%2012\%20-\%20Policy\%20EN.pdf

[19] Ontario Ministry of Education. Policy/program memorandum no. 138 , Online available from http://www.edu.gov.on.ca/extra/eng/ppm/138.html

[20] C. S. Barroso, S. H. Kelder, A. E. Springer, C. L. Smith, N. Ranjit, C. Ledingham, D. M. Hoelscher. Senate bill 42: Implementation and impact on physical activity in middle schools, Journal of Adolescent Health, Vol. 45, No. 3, S82-90, 2009.

[21] S. H. Kelder, A. E. Springer, C. S. Barroso, C. L. Smith, E. Sanchez, N. Ranjit, D. M. Hoelscher. Implementation of Texas senate bill 19 to increase physical activity in elementary schools, Journal of Public Health Policy, Vol. 30, No. S1, S221-47, 2009.

[22] E. S. Belansky, N. Cutforth, E. Delong, C. Ross, S. Scarbro, L. Gilbert, B. Beatty, J. A. Marshall. Early impact of the federally mandated local wellness policy on physical activity in rural, low-income elementary schools in Colorado. Journal of Public Health Policy, Vol. 30, No. S1, S141-60, 2009.

[23] L. C. Mâsse, D. Naiman, P. Naylor. From policy to practice: Implementation of physical activity and food policies in schools, International Journal of Behavioral Nutrition and Physical Activity, Vol. 10, No. 1, 71, 2013.

[24] S. Pitt Barnes, L. Robin, T. P. O'Toole, K. Dawkins, K. L. Kettel Khan, L. C. Leviton. Results of evaluability assessments of local wellness policies in 6 US school districts, Journal of School Health, Vol. 81, No. 8, 502-11, 2011.

[25] J. P. J. Taylor, M. L. M. McKenna, G. P. G. Butler. Monitoring and evaluating school nutrition and physical activity policies, Canadian Journal of Public Health, Vol. 101, No. S2, S24-7, 2010.

[26] K. McLeroy, D. Bibeau, A, Steckler, K. Glanz. An ecological perspective on health promotion programs. Health Education \& Behavior. Vol. 15, No. 4, 351-77, 1988.

[27] L. Richard, L. Gauvin, K. Raine. Ecological models revisited: Their uses and evolution in health promotion over two decades, Annual Review of Public Health, Vol. 32, 307-326, 2011.

[28] U. Bronfenbrenner. Toward an experimental ecology of human-development, American Psychologist, Vol. 32, No. 7, 513-31, 1977.

[29] L. Green, L. Richard, L. Potvin. Ecological foundations of health promotion, American Journal of Health Promotion. Vol. 10, No. 4, 270-81, 1996

[30] D. Stokols. Translating social ecological theory into guidelines for community health promotion, American Journal of Health Promotion, Vol. 10, No. 4, 282-98, 1996.

[31] T. M. Penhollow, K. E. Rhoads. Preventing obesity and promoting fitness: An ecological perspective, American Journal of Lifestyle Medicine, Vol. 8, No. 1, 21-4, 2014.

[32] B. Swinburn, G. Egger, F. Raza. Dissecting obesogenic environments: The development and application of a framework for identifying and prioritizing environmental interventions for obesity, Preventive Medicine, Vol. 29, No. 6, 563-70, 1999. 
[33] E. Hennessy, V. I. Kraak, R. R. Hyatt, J. Bloom, M. Fenton, C. Wagoner, C. D. Economos. Active living for rural children community perspectives using PhotoVOICE, American Journal of Preventive Medicine, Vol. 39, No. 6, 537-45, 2010.

[34] A. P. Belon, L. M. Nieuwendyk, H. Vallianatos, C. I. J. Nykiforuk. How community environment shapes physical activity: Perceptions revealed through the PhotoVoice method, Social Science \& Medicine, Vol. 116, 10-21, 2014.

[35] B. Lloyd, S. Dumbrell. Modifying the food supply at a community swimming pool: A case study, Health Promotion Journal of Australia, Vol. 22, No. 1, 22-6, 2011.

[36] M. M. Vine, S. J. Elliott. Examining local-level factors shaping school nutrition policy implementation in Ontario, Canada, Public Health Nutrition, Vol. 17, No. 6, 1290-8, 2014.

[37] M. M. Vine, S. J. Elliott, K. D. Raine. Exploring implementation of the Ontario school food and beverage policy at the secondary-school level: A qualitative study, Canadian Journal of Dietetic Practice and Research, Vol. 75, No. 3, 118-24, 2014

[38] S. Ramanathan, K. R. Allison, G. Faulkner, J. J. M. Dwyer. Challenges in assessing the implementation and effectiveness of physical activity and nutrition policy interventions as natural experiments, Health Promotion International, Vol. 23, No. 3, 290-7, 2008.

[39] J. E. Robertson-Wilson, L. Levesque. Ontario's daily physical activity policy for elementary schools: Is everything in place for success?, Canadian Journal of Public Health, Vol. 100, No. $2,125-9,2009$.

[40] Cancer Care Ontario \& Ontario Agency for Health Protection and Promotion (Public Health Ontario). Taking action to prevent chronic disease: Recommendations for a healthier Ontario, Online available from

https:/www.cancercare.on.ca/pcs/prevention/healthieron/?W T.mc_id=/takingaction

[41] M. He, L. Piche, C. Beynon, J. Kurtz, S. Harris. Screen-related sedentary behaviours of school-aged children: Principals' and teachers' perspectives, Health Education Journal, Vol. 70, No. 1, 32-8, 2011.

[42] M. R. Stone, G. E. Faulkner, L. Zeglen-Hunt, J. C. Bonne. The daily physical activity (DPA) policy in Ontario: Is it working? An examination using accelerometry-measured physical activity data, Canadian Journal of Public Health. Vol. 103, No. 3, 170-4, 2012.

[43] I. Patton. Teachers' perspectives of the daily physical activity program in Ontario. Physical \& Health Education Journal. Vol. 78, No. 1, 14-21, 2012.

[44] K. Albright, K. Gechter, A. Kempe. Importance of mixed methods in pragmatic trials and dissemination and implementation research, Academic Pediatrics, Vol. 13, No. 5, 400-7, 2013.

[45] B. F. Crabtree, W. L. Miller. Doing qualitative research, 2nd ed. Sage Publications, Inc., USA, 1999.

[46] M. Q. Patton. Qualitative evaluation and research methods. 3rd ed. Sage Publications, Inc., USA, 2002.

[47] M. B. Miles, A. M. Huberman. Qualitative data analysis: An expanded sourcebook, 2nd ed, Sage Publications, Inc., USA, 1994.

[48] H. E. Tjomsland. Sustaining comprehensive physical activity practice in elementary school: A case study applying mixed methods, Teachers and Teaching: Theory and Practice, Vol. 16, No. 1, 73-95, 2010.

[49] C. D. Kennedy, M. Cantell, D. Dewey. Has the Alberta daily physical activity initiative been successfully implemented in Calgary schools?, Paediatrics \& Child Health, Vol. 15, No. 7, E19-24, 2010.

[50] K. R. Evenson, K. Ballard, G. Lee, A. Ammerman. Implementation of a school-based state policy to increase physical activity, Journal of School Health, Vol. 79, No. 5, 231-8, 2009.

[51] J. Langille, W. Rodgers. Exploring the influence of a social ecological model on school-based physical activity, Health Education \& Behavior, Vol. 37, No. 6, 879-94, 2010.

[52] M. T. Mahar. Impact of short bouts of physical activity on attention-to-task in elementary school children, Preventive Medicine, Vol 52, No. S1, S60-4, 2011.

[53] Ontario Ministry of Education. The Ontario curriculum, Grades 1-8 health and physical education (interim edition), Online available fromhttp://www.edu.gov.on.ca/eng/curricul um/elementary/health.html

[54] V. Sánchez, R. Hale, M. Andrews, Y. Cruz, V. Bettencourt, P. Wexler, C. Halasan. School wellness policy implementation: Insights and recommendations from two rural school districts, Health Promotion Practice, Vol. 15, No. 3, 340-8, 2014.

[55] J. E. Robertson-Wilson, M. D. Dargavel, P. J. Bryden, B. Giles-Corti. Physical activity policies and legislation in schools: A systematic review, American Journal of Preventive Medicine. Vol. 43, No. 6, 643-9, 2012.

[56] Elementary Teachers' Federation of Ontario. ETFO encourages males in elementary, Online available from http://www.etfo.ca/SiteCollectionDocuments/Publication $\% 2$ 0Documents/Voice\%20-\%20School\%20Year\%202002-3/Sp ring\%202003/Encouraging_Male_Teachers.pdf

[57] J.-L. Bernard, D. Hill, P. Falter, W. D. Wilson. Narrowing the gender gap: Attracting men to teaching, Online available from http://professionallyspeaking.oct.ca/publications/PDF/Men_I n_Teaching_e.pdf

[58] M. Carter, B. Swinburn. Measuring the 'obesogenic' food environment in New Zealand primary schools, Health Promotion International. Vol. 19, No. 1, 15-20, 2004.

[59] J. A. Dean, S. J. Elliott. Prioritizing obesity in the city, Journal of Urban Health, Vol. 89, No. 1, 196-213, 2012.

[60] M. M. Vine, S. J. Elliott. Exploring the school nutrition policy environment in Canada using the ANGELO framework, Health Promotion Practice, Vol. 15, No. 3, 331-9, 2014.

[61] I. Ferreira, K. van der Horst, W. Wendel-Vos, S. Kremers, F. J. van Lenthe, J. Brug. Environmental correlates of physical activity in youth - a review and update, Obesity Reviews, Vol. 8, No. 2, 129-54, 2007.

[62] K. van der Horst, A. Oenema, I. Ferreira, W. Wendel-Vos, K. Giskes, F. van Lenthe, J. Brug. A systematic review of 
environmental correlates of obesity-related dietary behaviors in youth, Health Education Research, Vol. 22, No. 2, 203-26, 2007.
[63] S. F. L. Kirk, T. L. Penney, T.-F. McHugh. Characterizing the obesogenic environment: The state of the evidence with directions for future research, Obesity Reviews, Vol. 11, No. 2, 109-17, 2010. 